\title{
Thermodynamic Analysis for Binding of 4-O- $\beta$-tri- $N$-acetylchitotriosyl Moranoline, a Transition State Analogue Inhibitor for Hen Egg White Lysozyme
}

\author{
Makoto Ogata $^{1}$, Tamo Fukamizo ${ }^{2}$ and Takayuki Ohnuma ${ }^{2,3 *}$ \\ ${ }^{1}$ Faculty of Food and Agricultural Sciences, Fukushima University, Fukushima, Japan, ${ }^{2}$ Department of Advanced Bioscience, \\ Kindai University, Nara, Japan, ${ }^{3}$ Agricultural Technology and Innovation Research Institute(ATIRI), Kindai University, Nara, Japan
}

OPEN ACCESS

Edited by:

Hang Fai Kwok,

University of Macau, China

Reviewed by:

Gang Ma,

Hebei University, China

Yoonji Lee,

Chung-Ang University, South Korea

*Correspondence:

Takayuki Ohnuma

ohnumat@nara.kindai.ac.jp

Specialty section:

This article was submitted to

Protein Chemistry and Enzymology,

a section of the journal

Frontiers in Molecular Biosciences

Received: 17 January 2021

Accepted: 24 May 2021

Published: 10 June 2021

Citation:

Ogata M, Fukamizo T and Ohnuma T (2021) Thermodynamic Analysis for Binding of $4-\mathrm{O}-\beta$-tri- $\mathrm{N}$ -

acetylchitotriosyl Moranoline, a Transition State Analogue Inhibitor for

Hen Egg White Lysozyme.

Front. Mol. Biosci. 8:654706.

doi: 10.3389/fmolb.2021.654706
4-O- $\beta$-tri- $N$-acetylchitotriosyl moranoline $\left(\mathrm{GN}_{3} \mathrm{M}\right)$ is a transition-state analogue for hen egg white lysozyme (HEWL) and identified as the most potent inhibitor till date. Isothermal titration calorimetry experiments provided the thermodynamic parameters for binding of $\mathrm{GN}_{3} \mathrm{M}$ to HEWL and revealed that the binding is driven by a favorable enthalpy change $\left(\Delta H^{\circ}=-11.0 \mathrm{kcal} / \mathrm{mol}\right)$ with an entropic penalty $\left(-T \Delta S^{\circ}=2.6 \mathrm{kcal} / \mathrm{mol}\right)$, resulting in a free energy change $\left(\Delta G^{\circ}\right)$ of $-8.4 \mathrm{kcal} / \mathrm{mol}$ [Ogata et al. (2013) 288, 6,072-6,082]. Dissection of the entropic term showed that a favorable solvation entropy change $\left(-T \Delta S_{\text {solv }}{ }^{\circ}=-9.2 \mathrm{kcal} /\right.$ $\mathrm{mol})$ is its sole contributor. The change in heat capacity $\left(\Delta C_{\mathrm{p}}{ }^{\circ}\right)$ for the binding of $\mathrm{GN}_{3} \mathrm{M}$ was determined to be $-120.2 \mathrm{cal} / \mathrm{K} \cdot \mathrm{mol}$. These results indicate that the bound water molecules play a crucial role in the tight interaction between $\mathrm{GN}_{3} \mathrm{M}$ and $\mathrm{HEWL}$.

Keywords: 4-O- $\beta$-tri-N-acetylchitotriosyl moranoline, lysozyme (HEWL), thermodynamics, inhibitor, binding

\section{INTRODUCTION}

Lysozyme (EC 3.2.1.17) is an enzyme that hydrolyzes the $\beta$-1,4-glycosidic bond between $\mathrm{N}$-acetylmuramic acid and $\mathrm{N}$-acetylglucosamine (GlcNAc) in peptidoglycan, a major structural component of the bacterial cell wall (Jollès and Jollès, 1984). Hen egg white lysozyme (HEWL) is the first enzyme to have its three-dimensional structure determined by X-ray diffraction (Blake et al., 1965), consequently its catalytic mechanism has been intensively studied. Based on the modeled structure of HEWL-chitohexaose, it was proposed that HEWL has six subsites for binding of sugar residues in the active site cleft, termed -4 to +2 (formerly A, B, C, D, E, and F), and the cleavage occurs between sugars located at subsites -1 and +1 through the cooperative action of Glu35 and Asp52 (Johnson and Phillips, 1965; Blake et al., 1967; Phillips, 1967). In the catalytic reaction, Glu35 is thought to act as a general acid catalyst to protonate the glycosidic oxygen, while Asp52 acts as a conjugate base and stabilizes the carbonium ion intermediate that adopts a half-chair conformation with $\mathrm{C} 1$ carbon displaying $s p^{2}$ hybridization. This is known as the Phillips mechanism, widely supported by a number of experimental observations including mutagenesis studies of these amino acids (Malcolm et al., 1989).

Abbreviations: GlcNAc, $N$-acetyl- $\beta$-D-glucosamine; $(\mathrm{GlcNAc})_{n}, \beta$-1,4-linked oligosaccharide of GlcNAc with a polymerization degree of $\mathrm{n} ; \mathrm{GN}_{3} \mathrm{M}, 4-\mathrm{O}-\beta$-tri- $N$-acetylchitotriosyl moranoline; HEWL, hen egg white lysozyme; ITC, isothermal titration calorimetry; NAG2FGlcF, 2-Acetamido-2-deoxy- $\beta$-D-glucopyranosyl-(1 $\rightarrow 4)$-2-deoxy-2-fluoro- $\beta$-D-glucopyranosylfluoride. 


\section{Binding affinity to $\mathrm{HEWL}$}
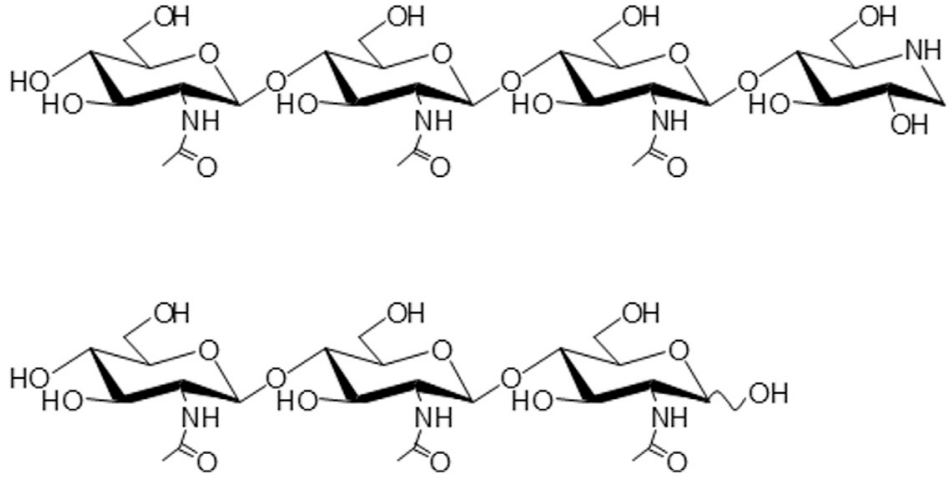

$K_{\mathrm{d}}=0.76 \mu \mathrm{M}$

$\Delta G=-8.4 \mathrm{kcal} / \mathrm{mol}$
$K_{\mathrm{d}}=9.3 \mu \mathrm{M}$

$\Delta G=-6.9 \mathrm{kcal} / \mathrm{mol}$

FIGURE 1 | Chemical structure of $\mathrm{GN}_{3} \mathrm{M}$ and $(\mathrm{GlcNAc})_{3}$.

Meanwhile, Vocadlo et al. reported the crystal structure of HEWL, covalently bound to $\mathrm{C} 1$ carbon of the -1 sugar, which exhibits a chair conformation with $\mathrm{C} 1$ carbon in $s p^{3}$ hybridization (Vocadlo et al., 2001). Recently, we synthesized 4-O- $\beta$-tri$\mathrm{N}$-acetylchitotriosyl moranoline $\left(\mathrm{GN}_{3} \mathrm{M}\right)$ from chitoteratetraose $(\mathrm{GlcNAc})_{4}$ and moranoline with the aid of the lysozyme-catalyzed transglycosylation reaction and examined its inhibitory action toward HEWL (Figure 1) (Ogata et al., 2013). GN ${ }_{3} \mathrm{M}$ with $\mathrm{Cl}$ carbon in $s p^{3}$ hybridization was found to be the most potent lysozyme inhibitor till date with an inhibition constant $K_{\mathrm{i}}$ of $1.84 \mu \mathrm{M}$ and bind tightly to HEWL $\left(K_{\mathrm{d}}=0.76 \mu \mathrm{M}\right.$ at $\left.25^{\circ} \mathrm{C}\right)$. Furthermore, in the HEWL-GN $\mathrm{H}_{3} \mathrm{M}$ complex structure, $\mathrm{GN}_{3} \mathrm{M}$ was well superimposed on NAG2FGlcF ((GlcNAc) $)_{2}$-fluoro-glucosyl fluoride), covalently bound to HEWL mutant E35Q and the moranoline moiety bound to subsite -1 was in a chair conformation (without distortion) as the -1 sugar of the covalently bound NAG2FGlcF. From these results, we concluded to support the covalent glycosyl-enzyme intermediate formation in the reaction catalyzed by the wild-type HEWL. This is known as the Koshland mechanism, now more widely accepted by enzyme researchers (Koshland, 1953).

In this study, in order to elucidate the driving forces responsible for the tight binding of $\mathrm{GN}_{3} \mathrm{M}$ (a transition-state analogue inhibitor) to HEWL, we conducted a detailed thermodynamic analysis using isothermal titration calorimetry. The thermodynamic data obtained from our study would be useful to understand the substrate binding mechanism of HEWL and to design novel glycosidase inhibitors with moranoline moiety.

\section{MATERIALS AND METHODS}

\section{Materials}

4-O- $\beta$-tri-N-acetylchitotriosyl moranoline $\left(\mathrm{GN}_{3} \mathrm{M}\right)$ was prepared by lysozyme-mediated transglycosylation from the substrates tetra- $N$-acetylchitotetraose $(\mathrm{GlcNAc})_{4}$, and moranoline (1deoxynojirimycin) as described previously (Ogata et al., 2013). HEWL, which was recrystallized six times, was purchased from Seikagaku Kogyo Co. (Tokyo, Japan). All other reagents were of the highest quality commercially available and were used without further purification.

\section{Isothermal Titration Calorimetry (ITC) Experiments}

The HEWL solution $(45 \mu \mathrm{M})$ in $20 \mathrm{mM}$ phosphate buffer $(\mathrm{pH}$ 7.0) was degassed and its concentration was determined by measuring the absorbance of ultraviolet light at $280 \mathrm{~nm}$. $\mathrm{GN}_{3} \mathrm{M}$ was dissolved $(0.5 \mathrm{mM})$ in $20 \mathrm{mM}$ phosphate buffer $(\mathrm{pH}$ 7.0), degassed, and loaded into a syringe, whereas the HEWL solution $(0.2028 \mathrm{ml})$ was loaded into the sample cell. Calorimetric titration was performed with an $\mathrm{iTC}_{200}$ system (Microcal Northampton, MA, United States). For the titrations, $2.5 \mu \mathrm{l}$ of a ligand was injected into the sample cell at an interval of $180 \mathrm{~s}$ with a stirring speed of 1,000 rpm. The heat of dilution caused by an injection of $\mathrm{GN}_{3} \mathrm{M}$ was measured under identical buffer, injection, and temperature conditions but by adding ligand to a sample solution that lacked protein. The heat of dilution was subtracted from the heat change that occurred in presence of the protein. Origin ${ }^{\circledR}$ software was used to analyze the ITC data. Using the single-site binding model, individual datasets obtained from the titration experiments fitted well to the theoretical curves, providing stoichiometries $(n)$, equilibrium binding association constants $\left(K_{\mathrm{a}}\right)$, and enthalpy changes $\left(\Delta H^{\circ}\right)$ of the protein-ligand interactions. The value of $n$ was found to be between 1.02 and 1.22 for all titrations. The binding free energy change $\left(\Delta G^{\circ}\right)$ and the entropy change $\left(\Delta S^{\circ}\right)$ were calculated from the relationship described in Eq. 1.

$$
\Delta G^{\circ}=-R T \cdot \ln K_{\mathrm{a}}=\Delta H^{\circ}-T \Delta S^{\circ}
$$

To examine temperature dependence, ITC measurements were performed at $\mathrm{pH} 7.0$ and the temperature was varied in fivedegree increments from 15 to $35^{\circ} \mathrm{C}$. Methods for obtaining the heat capacity change $\left(\Delta C_{\mathrm{p}}{ }^{\circ}\right)$ and parameterizing the entropic term have been described previously (Ohnuma et al., 2011). Briefly, the binding heat capacity change $\left(\Delta C_{\mathrm{p}}{ }^{\circ}\right)$ was obtained from the ITC titrations over temperature range. Measurements of temperature dependence of $\Delta H^{\circ}$ for $\mathrm{GN}_{3} \mathrm{M}$ binding to HEWL in 


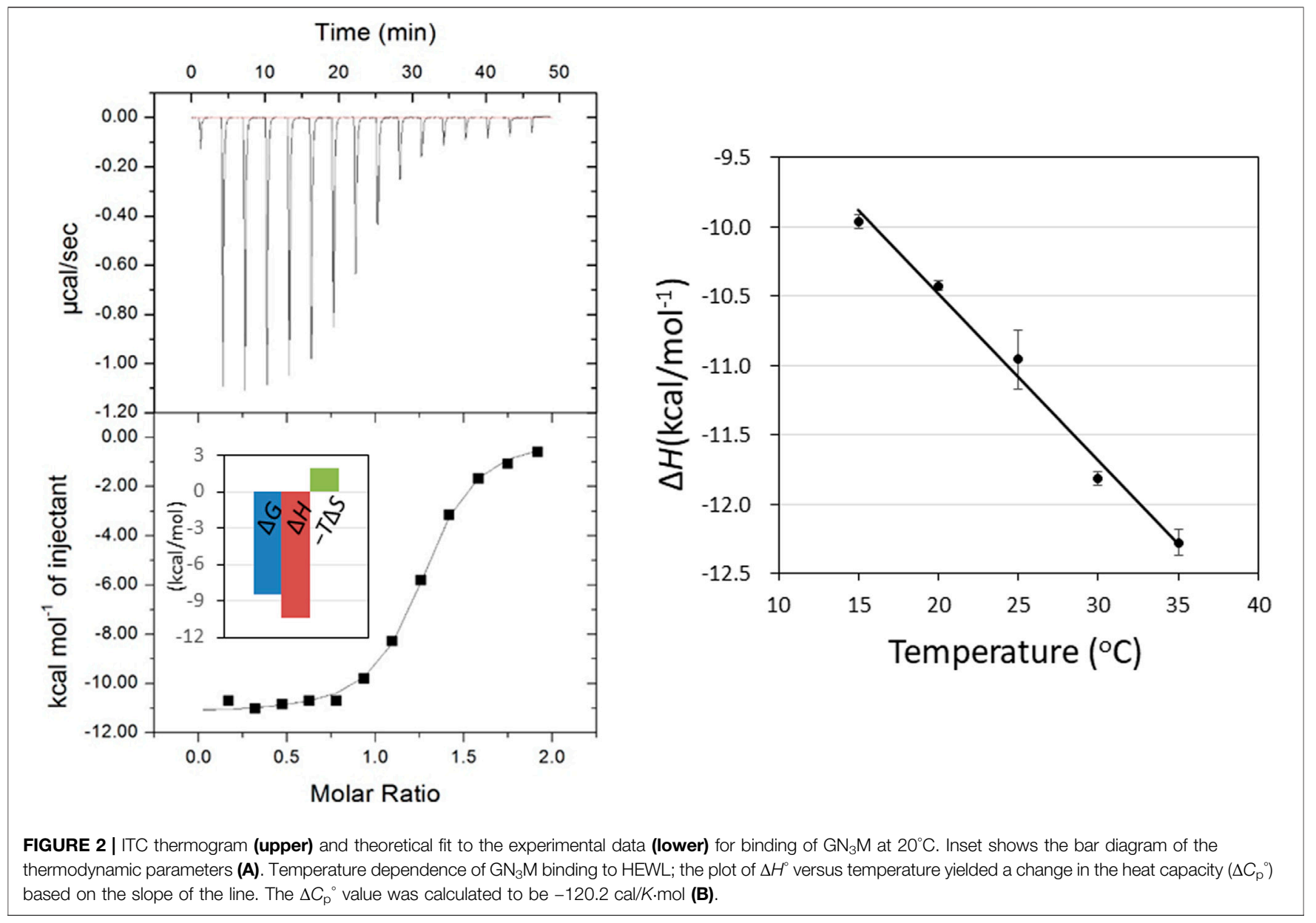

the temperature range yielded a straight line of slope equal to $\Delta C_{\mathrm{p}}{ }^{\circ}$. Errors are reported as standard deviations of at least three experiments at each temperature.

\section{RESULTS AND DISCUSSION}

In addition to chitin oligosaccharides $(\mathrm{GlcNAc})_{\mathrm{n}}(n=2-3)$, we previously investigated the inhibitory effects of 4 - $O-\beta$-tri$N$-acetylchitotriosyl-2-acetamido-2,3-dideoxydidehydroglucopyranose $\left(\mathrm{GN}_{3} \mathrm{D}\right)$, 4-O- $\beta$-tri- $N$-acetylchitotoriosyl-2-acetamido-2,3dideoxydidehydroglucono- $\delta$-lactone $\left(\mathrm{GN}_{3} \mathrm{~L}\right)$, and 4-O$\beta$-tri-N-acetylchitotriosyl moranoline $\left(\mathrm{GN}_{3} \mathrm{M}\right)$ against HEWL (Figure 1). $\mathrm{GN}_{3} \mathrm{M}$ was found to be the most potent inhibitor $\left(K_{\mathrm{i}}=1.84 \mu \mathrm{M}\right)$. Based on the thermodynamic parameters provided by ITC experiments for HEWL binding of these compounds, $\mathrm{GN}_{3} \mathrm{M}$ was found to be a tight binding inhibitor $\left(\Delta G^{\circ}=-8.4 \mathrm{kcal} / \mathrm{mol} ; K_{\mathrm{d}}=0.76 \mathrm{M}\right)($ Ogata et al., 2013). Figure 2A shows a typical ITC thermogram and theoretical fit to the experimental data for binding of $\mathrm{GN}_{3} \mathrm{M}$ at $20^{\circ} \mathrm{C}$. Figure $3 \mathrm{~A}$ shows superimposed structures of $(\mathrm{GlcNAc})_{3}$-liganded HEWL (PDB code 1lzb) and $\mathrm{GN}_{3} \mathrm{M}$-liganded HEWL (PDB code 4hp0) complexes (Maenaka et al., 1995; Ogata et al., 2013). The main chain of $\mathrm{GN}_{3} \mathrm{M}$-liganded HEWL overlapped well with that of
(GlcNAc) ${ }_{3}$-liganded HEWL with a RMS deviation of $0.235 \AA$ in the superimposition of the corresponding $128 \mathrm{Ca}$-atoms. The (GlcNAc) $)_{3}$ moiety of $\mathrm{GN}_{3} \mathrm{M}$ bound to HEWL also overlapped with $(\mathrm{GlcNAc})_{3}$ bound to HEWL. All saccharide rings in the complex structures were in the ${ }^{4} C_{1}$ chair conformation with small variations. Thus, the potent inhibitory activity and tight binding ability of $\mathrm{GN}_{3} \mathrm{M}$ (a (GlcNAc) ${ }_{3}$-moranoline conjugate) towards HEWL, in comparison to other compounds may be attributed to the moranoline moiety of $\mathrm{GN}_{3} \mathrm{M}$. The $\Delta G^{\circ}$ value for $(\mathrm{GlcNAc})_{3}$ binding to HEWL was found to be $-6.9 \mathrm{kcal} / \mathrm{mol}$. In this case, $(\mathrm{GlcNAc})_{3}$ binds to the subsites $-4,-3$, and -2 of HEWL, as shown in the crystal structure of the HEWL$\left(\right.$ GlcNAc) ${ }_{3}$ complex (Figure 3B, left). Therefore, it appears that moranoline residue attached to the reducing end of $(\mathrm{GlcNAc})_{3}$ contributes to the binding free energy of $-2.5 \mathrm{kcal} / \mathrm{mol}\left(\Delta \Delta G^{\circ}=-8.4-(-6.9) \mathrm{kcal} / \mathrm{mol}\right)$, resulting in a 12.2 -fold enhancement in the binding affinity $\left(K_{\mathrm{d}}\right.$ of $0.76 \mu \mathrm{M}$ for $\mathrm{GN}_{3} \mathrm{M}$ and $9.3 \mu \mathrm{M}$ for $\left.(\mathrm{GlcNAc})_{3}\right)$. Williams et al. synthesized the xylobio-deoxynojirimycin analogue (a xylanase inhibitor and xylose-moranoline conjugate) and demonstrated that it binds to the retaining family of 10 xylanase Cex from Cellulomonas fimi approximately 830-fold more tightly than xylobiose ( $K_{\mathrm{i}}$ of $5.8 \mu \mathrm{M}$ for xylobio-deoxynojirimycin analogue and 4,800 $\mu \mathrm{M}$ for xylobiose) (Williams et al., 2000). Arai et al. 

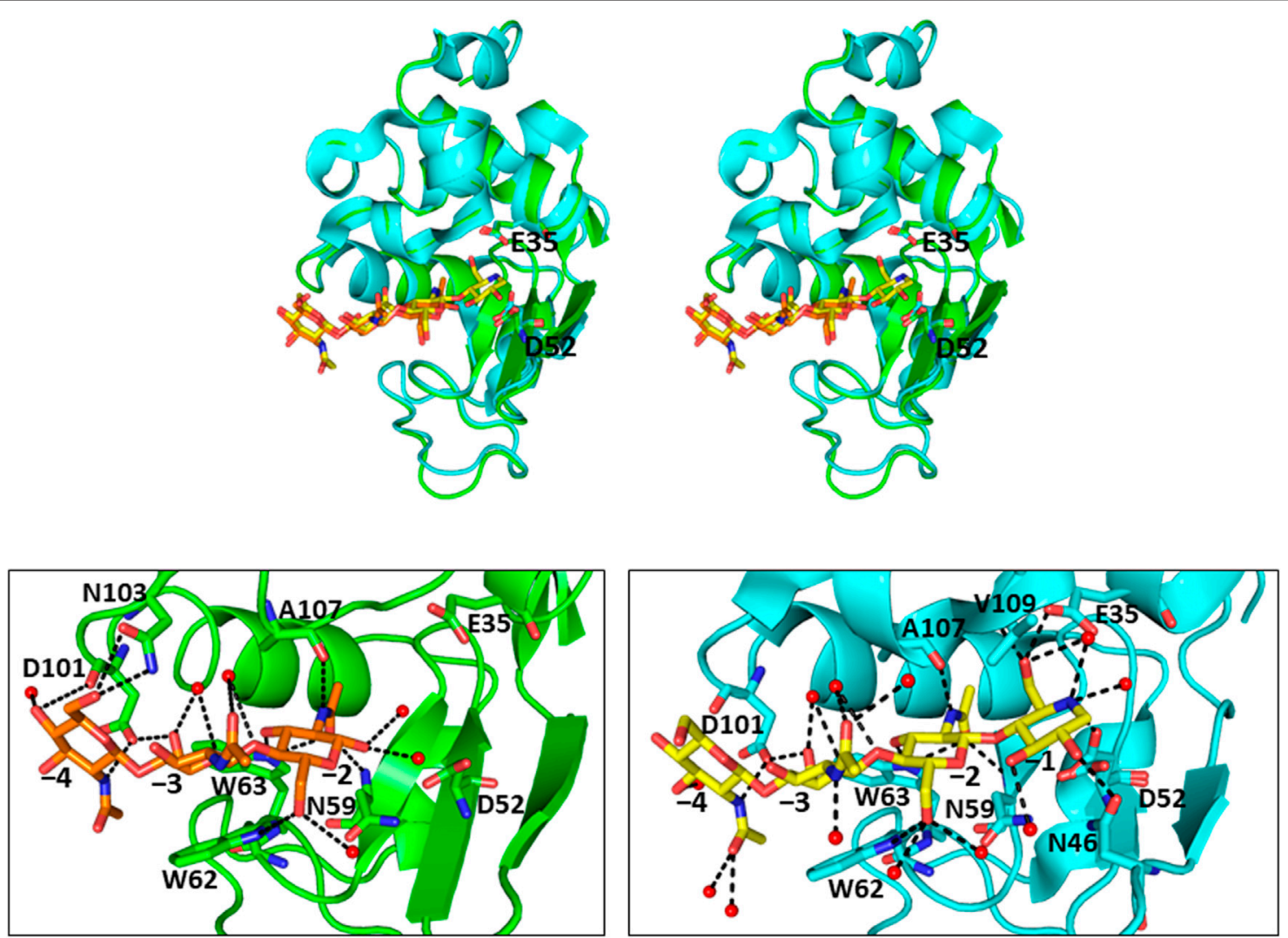

FIGURE 3 | Crystal structures of (GlcNAc) 3 -liganded and $\mathrm{GN}_{3} \mathrm{M}$-liganded HEWL (A) Stereo view of superimposed structures of (GlcNAc) 3 -liganded HEWL (green; PDB code $1 \mathrm{lzb}$ ) and $\mathrm{GN}_{3} \mathrm{M}$-liganded HEWL (cyan; PDB code 4hp0) complexes. The catalytic residues Glu35 and Asp52 of HEWL are indicated as sticks (GlcNAc) ${ }_{3}$ and $\mathrm{GN}_{3} \mathrm{M}$ are shown as orange and yellow sticks, respectively. (B) The binding modes of $(\mathrm{GlCNAc})_{3}$ and $\mathrm{GN}_{3} \mathrm{M}$ to HEWL. Amino acid residues involved in the binding of ligands $(\mathrm{GlcNAc})_{3}$ and $\mathrm{GN}_{3} \mathrm{M}$ are also indicated as sticks. The numbers, -4 to -1 , indicate the subsite positions. Dashed lines indicate the possible hydrogen bonds. Red spheres represent oxygen atoms of water molecules.

TABLE 1 | Parameterization of the entropic term for binding of $\mathrm{GN}_{3} \mathrm{M}$ to $\mathrm{HEWL}$ at $25^{\circ} \mathrm{C}$.

\begin{tabular}{|c|c|c|c|c|}
\hline 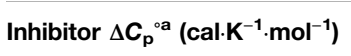 & $-T \Delta S^{\circ}\left(\mathrm{kcal}^{\left.-\mathrm{mol}^{-1}\right)}\right.$ & $-T \Delta S_{\operatorname{mix}}{ }^{{ }^{\mathrm{bb}}}\left({\left.\mathrm{kcal} \cdot \mathrm{mol}^{-1}\right)}^{-1}\right.$ & $-T \Delta S_{\text {solv }}{ }^{\circ \mathrm{c}}\left({\left.\mathrm{kcal} \cdot \mathrm{mol}^{-1}\right)}^{-1}\right.$ & $-T \Delta S_{\text {conf }}{ }^{\text {d }}\left(\mathrm{kcal}^{\left.-\mathrm{mol}^{-1}\right)}\right.$ \\
\hline $\mathrm{GN}_{3} \mathrm{M}-120.2$ & 2.6 & 2.4 & -9.2 & 9.3 \\
\hline
\end{tabular}

${ }^{a}$ Data are derived from the temperature dependence of $\Delta \mathrm{H}^{\circ}$.

${ }^{b} \Delta \mathrm{S}_{\text {mix }}{ }^{\circ}=\mathrm{R} / \mathrm{n}(1 / 55.5)=-8 \mathrm{cal} / \mathrm{K} \mathrm{mol}$ (Baker and Murphy, 1997).

${ }^{c} \Delta \mathrm{S}_{\text {solv }}{ }^{\circ}=\Delta \mathrm{C}_{p} \ln \left(\mathrm{T}_{298} \mathrm{~K} / \mathrm{T}_{385} \mathrm{~K}\right)$ (Baldwin, 1986; Murphy et al., 1990; Baker and Murphy, 1997).

${ }^{d}$ Derived using $\Delta \mathrm{S}^{\circ}=\Delta \mathrm{S}_{\text {Solv }}{ }^{\circ}+\Delta \mathrm{S}_{\text {mix }}{ }^{\circ}+\Delta \mathrm{S}_{\text {conf }}$ (Baker and Murphy, 1997).

synthesized (glucose) $)_{\mathrm{n}}$-deoxynojirimycin $(n=1-8)$ conjugates by the transglucosylation action of bacterial saccharifying amylases and showed that these compounds have inhibitory activity against $\alpha$ - and $\beta$-amylases of various origins (Arai et al., 1986). Therefore, conjugation of moranoline to the reducing end site of mono- or oligosaccharides is an excellent strategy to design potent inhibitors of the target glycosidases. Since $\mathrm{GN}_{3} \mathrm{M}$ lacks an acetamido group at the $\mathrm{C} 2$ of the moranoline moiety bound to the -1 subsite of HEWL (Figure 3B, right), conjugation of $\mathrm{N}$-acetylmoranoline to the reducing end of $(\mathrm{GlcNAc})_{3}$ could improve the inhibitory activity of $(\text { GlcNAc) })_{3}$ (de la Fuentea et al., 2016).
Determination of temperature dependence of $\Delta H^{\circ}$ for binding of $\mathrm{GN}_{3} \mathrm{M}$ at $\mathrm{pH} 7.0$ in the temperature range of $15-35^{\circ} \mathrm{C}$, yields a change in the reaction heat capacity $\left(\Delta C_{\mathrm{p}}{ }^{\circ}\right)$ (Figure $\left.2 \mathrm{~B}\right)$. The $\Delta C_{\mathrm{p}}{ }^{\circ}$ value for $\mathrm{GN}_{3} \mathrm{M}$ binding to HEWL was found to be $-120.2 \mathrm{cal} / \mathrm{K} \cdot \mathrm{mol}$ (Table $\mathbf{1}$ ). Negative heat capacity changes are often attributed to the release of well-ordered water molecules from the interface between the protein and the ligand into a bulk solvent by forming hydrophobic contacts. Therefore, we decomposed the entropic terms for binding of $\mathrm{GN}_{3} \mathrm{M}$ to HEWL as follows. By recognizing that the entropy of solvation is close to zero for proteins near $385 \mathrm{~K}, \Delta C_{\mathrm{p}}{ }^{\circ}$ can be related to the solvation entropy change $\left(\Delta S_{\text {solv }}{ }^{\circ}\right)$ of the binding reaction at $\mathrm{t}=$ 
TABLE 2 | The solvent accessible surface areas (ASAs) of ligand-bound and ligand-free HEWL.

\begin{tabular}{lccc} 
Structures & $\boldsymbol{A S}_{\text {apolar }}\left(\AA^{\mathbf{2}}\right)$ & $\boldsymbol{A S A}_{\text {polar }}\left(\AA^{\mathbf{2}}\right)$ & $\boldsymbol{A S A}_{\text {total }}\left(\AA^{\mathbf{2}}\right)$ \\
\hline HEWL & 3,628 & 2,850 & 6,478 \\
HEWL-GN ${ }_{3} \mathrm{M}$ & 3,172 & 2,598 & 5,771 \\
HEWL-(GlcNAc) & 3,690 & 2,875 & 6,566
\end{tabular}

GetArea 1.1 software was used for calculating the ASAs from the crystal structures of HEWL (PDB ID: 1lzd), GN ${ }_{3}$ M-liganded HEWL (PDB ID: 4hpO) and (GICNAc) ${ }_{3}$-liganded HEWL (PDB ID: 1/zb). This program separates the solvent accessible surface area

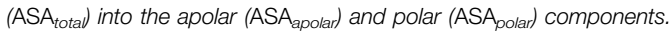

$25^{\circ} \mathrm{C}$ as described in Eq. 2 (Baldwin, 1986; Murphy et al., 1990; Baker and Murphy, 1997).

$$
\Delta S_{\text {solv }}{ }^{\circ}=\Delta C_{\mathrm{p}}{ }^{\circ} \ln \left(\mathrm{T}_{298 \mathrm{~K}} / T_{385 \mathrm{~K}}\right)
$$

Furthermore, the mixing entropy change $\left(\Delta S_{\text {mix }}{ }^{\circ}\right)$ is a statistical correction that reflects mixing of solute and solvent molecules and the changes in translational/rotational degrees of freedom as described in Eq. 3 (Baker and Murphy, 1997).

$$
\Delta S_{\text {mix }}{ }^{\circ}=R \ln (1 / 55.5)=-8 \mathrm{cal} / K \cdot \mathrm{mol}
$$

The conformational entropy change $\left(\Delta S_{\text {conf }}{ }^{\circ}\right)$ details the change in side-chain and backbone conformational entropy associated with binding. The reaction entropy change $\left(\Delta S^{\circ}\right)$, which is derived from the ITC experiment, can be viewed as the sum of $\Delta S_{\text {solv }}^{\circ}, \Delta S_{\text {mix }}{ }^{\circ}$ and $\Delta S_{\text {conf }}$ (Baker and Murphy, 1997). The results summarized in Table 1 show that at $\mathrm{pH} 7.0-T \Delta S_{\text {solv }}{ }^{\circ}$ is equal to $-9.2 \mathrm{kcal} / \mathrm{mol}\left(\Delta S_{\text {solv }}{ }^{\circ}=30.8 \mathrm{cal} / K \cdot \mathrm{mol}\right),-T \Delta S_{\text {mix }}{ }^{\circ}=$ $2.4 \mathrm{kcal} / \mathrm{mol}\left(\Delta S_{\text {mix }}{ }^{\circ}=-8.0 \mathrm{cal} / K \cdot \mathrm{mol}\right)$ and $-T \Delta S_{\text {conf }}$ is equal to $9.3 \mathrm{kcal} / \mathrm{mol}\left(\Delta S_{\text {conf }}{ }^{\circ}=-31.1 \mathrm{cal} / K \cdot \mathrm{mol}\right)$. As shown in Table 1 , while the $-T \Delta S_{\text {solv }}^{\circ}$ value for binding was negative $(-9.2 \mathrm{kcal} /$ $\mathrm{mol})$, the $-T \Delta S_{\text {conf }}$ value was positive $(9.3 \mathrm{kcal} / \mathrm{mol})$, resulting in a net entropic penalty of $2.6 \mathrm{kcal} / \mathrm{mol}$. These results indicate that the favorable solvation entropy change is the only contributor in the entropic term. A negative value of $-T \Delta S_{\text {solv }}{ }^{\circ}$ (positive value of $\Delta S_{\text {solv }}{ }^{\circ}$ ) implies water molecules are expulsed upon ligand binding due to hydrophobic interactions. Although the precise information regarding the solvation state of HEWL before and after binding to $\mathrm{GN}_{3} \mathrm{M}$ is not available, upon $\mathrm{GN}_{3} \mathrm{M}$ binding to HEWL, the apolar solvent accessible surface area $\left(A S A_{\text {apolar }}\right)$ was reduced with over $7 \%$. On the other hand, the same difference in $A S A_{\text {apolar }}$ between $(\mathrm{GlcNAc})_{3}$-bond and ligand free HEWL was

\section{REFERENCES}

Arai, M., Sumida, M., Fukuhara, K., Kainosho, M., and Murao, S. (1986). Isolation and Characterization of Amylase Inhibitors, (Glucose) ${ }_{\mathrm{n}}$-Deoxynojirimycin. Agric. Biol. Chem. 50, 639-644. doi:10.1080/00021369.1986.10867440

Baker, B. M., and Murphy, K. P. (1997). Dissecting the Energetics of a Protein-Protein Interaction: the Binding of Ovomucoid Third Domain to Elastase 1 1Edited by P. E. Wright. J. Mol. Biol. 268, 557-569. doi:10.1006/jmbi.1997.0977

Baldwin, R. L. (1986). Temperature Dependence of the Hydrophobic Interaction in Protein Folding. Proc. Natl. Acad. Sci. 83, 8069-8072. doi:10.1073/pnas.83.21. 8069 negligibly small (calculated using GetArea 1.1, TX, United States, based on the crystal structures to ligand-bound and ligand-free HEWL) (Table 2) (Fraczkiewicz and Braun, 1998). Figure 3B shows the binding modes of $(\mathrm{GlcNAc})_{3}$ and $\mathrm{GN}_{3} \mathrm{M}$ to HEWL. Compared to the HEWL-(GlcNAc) ${ }_{3}$ complex structure, more water molecules were observed at HEWL-GN ${ }_{3} \mathrm{M}$ interfaces. However, the solvation entropy change upon $\mathrm{GN}_{3} \mathrm{M}$ binding to HEWL is favorable (positive) (Table 1). Therefore, it is likely that dehydration for $\mathrm{GN}_{3} \mathrm{M}$ binding involves the ligand, the active site, or, in case of conformational changes upon binding, the bulk of protein.

In this study, the thermodynamic analysis for binding of $\mathrm{GN}_{3} \mathrm{M}$ yielded valuable information regarding the driving forces behind the tight binding of this inhibitor. In addition to the enthalpic contribution, the favorable solvation entropy change is the only contributor in the entropic term. Since they mimic the transition states of the hydrolytic reactions, iminosugar-conjugated glycosidase inhibitors containing moranoline residues have been designed and synthesized (Arai et al., 1986; Notenboom et al., 2000; Williams et al., 2000; Kato et al., 2011). They are known to have potent inhibitory activity against the target glycosidases. Therefore, it would be relevant to consider their thermodynamic properties for binding to the target enzymes, especially the solvation entropy change, in the rational design of novel inhibitors with improved properties.

\section{DATA AVAILABILITY STATEMENT}

The raw data supporting the conclusions of this article will be made available by the authors, without undue reservation.

\section{AUTHOR CONTRIBUTIONS}

MO, TF, and TO designed research; MO performed experiments; $\mathrm{MO}, \mathrm{TF}$, and TO analyzed the data; and TO wrote the paper.

\section{FUNDING}

This study was supported in part by a grant from Agricultural Technology and Innovation Research Institute (ATIRI), Kindai University.

Blake, C. C., Johnson, L. N., Mair, G. A., North, A. C., Phillips, D. C., and Sarma, V. R. (1967). Crystallographic Studies of the Activity of Hen Egg-white Lysozyme. Proc. R. Soc. Lond. B Biol. Sci. 167, 378-388. doi:10.1098/rspb.1967.0035

Blake, C. C. F., Koenig, D. F., Mair, G. A., North, A. C. T., Phillips, D. C., and Sarma, V. R. (1965). Structure of Hen Egg-White Lysozyme: A Three-Dimensional Fourier Synthesis at $2 \AA$ Resolution. Nature 206, 757-761. doi:10.1038/ 206757a0

de la Fuente, A., Rísquez-Cuadro, R., Verdaguer, X., García Fernández, J. M., Nanba, E., Higaki, K., et al. (2016). Efficient Stereoselective Synthesis of 2-Acetamido-1, 2-Dideoxyallonojirimycin (DAJNAc) and Sp2Iminosugar Conjugates: Novel Hexosaminidase Inhibitors with Discrimination Capabilities between the Mature and Precursor Forms 
of the Enzyme. Eur. J. Med. Chem. 121, 926-938. doi:10.1016/j.ejmech. 2015.10 .038

Fraczkiewicz, R., and Braun, W. (1998). Exact and Efficient Analytical Calculation of the Accessible Surface Areas and Their Gradients for Macromolecules. J. Comput. Chem. 19, 319-333. doi:10.1002/(sici)1096-987x(199802)19: 3<319::aid-jcc6>3.0.co;2-w

Johnson, L. N., and Phillips, D. C. (1965). Structure of Some Crystalline LysozymeInhibitor Complexes Determined by X-Ray Analysis at $6 \AA$ Resolution. Nature 206, 761-763. doi:10.1038/206761a0

Jollès, P., and Jollès, J. (1984). Review of Progress in Lysozyme Research. Mol. Cel. Biochem. 53, 165-189. doi:10.1007/BF00285225

Kato, E., Iwano, N., Yamada, A., and Kawabata, J. (2011). Synthesis and $\alpha$-amylase Inhibitory Activity of Glucose-Deoxynojirimycin Conjugates. Tetrahedron 67, 7692-7702. doi:10.1016/j.tet.2011.08.012

Koshland, D. E. (1953). Stereochemistry and the Mechanism of Enzymatic Reactions. Biol. Rev. 28, 416-436. doi:10.1111/j.1469-185x.1953.tb01386.x

Maenaka, K., Matsushima, M., Song, H., Sunada, F., Watanabe, K., and Kumagai, I. (1995). Dissection of Protein-Carbohydrate Interactions in Mutant Hen Eggwhite Lysozyme Complexes and Their Hydrolytic Activity. J. Mol. Biol. 247, 281-293. doi:10.1006/jmbi.1994.0139

Malcolm, B. A., Rosenberg, S., Corey, M. J., Allen, J. S., de Baetselier, A., and Kirsch, J. F. (1989). Site-directed Mutagenesis of the Catalytic Residues Asp-52 and Glu-35 of Chicken Egg white Lysozyme. Proc. Natl. Acad. Sci. 86, 133-137. doi:10.1073/pnas.86.1.133

Murphy, K., Privalov, P., and Gill, S. (1990). Common Features of Protein Unfolding and Dissolution of Hydrophobic Compounds. Science 247, 559-561. doi:10.1126/science.2300815

Notenboom, V., Williams, S. J., Hoos, R., Withers, S. G., and Rose, D. R. (2000). Detailed Structural Analysis of Glycosidase/Inhibitor Interactions: Complexes of Cex from Cellulomonas Fimiwith Xylobiose-Derived Aza-Sugars. Biochemistry 39, 11553-11563. doi:10.1021/bi0010625
Ogata, M., Umemoto, N., Ohnuma, T., Numata, T., Suzuki, A., Usui, T., et al. (2013). A Novel Transition-State Analogue for Lysozyme, 4-O- $\beta$-Tri-NAcetylchitotriosyl Moranoline, provided Evidence Supporting the Covalent Glycosyl-Enzyme Intermediate. J. Biol. Chem. 288, 6072-6082. doi:10.1074/jbc. m112.439281

Ohnuma, T., Sørlie, M., Fukuda, T., Kawamoto, N., Taira, T., and Fukamizo, T. (2011). Chitin Oligosaccharide Binding to a Family GH19 Chitinase from the moss Bryum Coronatum. FEBS J. 278, 3991-4001. doi:10.1111/j.1742-4658. 2011.08301.x

Phillips, D. C. (1967). The Hen Egg-white Lysozyme Molecule. Proc. Natl. Acad. Sci. U.S.A. 57, 484-495. doi:10.1073/pnas.57.3.483

Vocadlo, D. J., Davies, G. J., Laine, R., and Withers, S. G. (2001). Catalysis by Hen Egg-white Lysozyme Proceeds via a Covalent Intermediate. Nature 412, 835-838. doi:10.1038/35090602

Williams, S. J., Hoos, R., and Withers, S. G. (2000). Nanomolar versus Millimolar Inhibition by Xylobiose-Derived Azasugars: Significant Differences between Two Structurally Distinct Xylanases. J. Am. Chem. Soc. 122, 2223-2235. doi:10. 1021/ja993805j

Conflict of Interest: The authors declare that the research was conducted in the absence of any commercial or financial relationships that could be construed as a potential conflict of interest.

Copyright $\odot 2021$ Ogata, Fukamizo and Ohnuma. This is an open-access article distributed under the terms of the Creative Commons Attribution License (CC BY). The use, distribution or reproduction in other forums is permitted, provided the original author(s) and the copyright owner(s) are credited and that the original publication in this journal is cited, in accordance with accepted academic practice. No use, distribution or reproduction is permitted which does not comply with these terms. 